\title{
The curcumin analogue hydrazinocurcumin exhibits potent suppressive activity on carcinogenicity of breast cancer cells via STAT3 inhibition
}

\author{
XIAOFEI WANG ${ }^{*}$, YAN ZHANG*, XIWEN ZHANG, WENXIA TIAN, WENLI FENG and TINGMEI CHEN
}

Key Laboratory of Diagnostic Medicine Designated by the Ministry of Education, Chongqing Medical University, Chongqing 400016, P.R. China

Received August 30, 2011; Accepted October 24, 2011

DOI: $10.3892 /$ ijo.2011.1298

\begin{abstract}
Curcumin, the active component of turmeric, has been shown to protect against carcinogenesis and prevent tumor development in cancer. In our study, we tested the efficacy of a synthetic curcumin analogue, known as hydrazinocurcumin (HC), in breast cancer cells. The results demonstrated that compared to curcumin, $\mathrm{HC}$ was more effective in inhibiting STAT3 phosphorylation and downregulation of an array of STAT3 downstream targets which contributed to suppression of cell proliferation, loss of colony formation, depression of cell migration and invasion as well as induction of cell apoptosis. It was concluded that $\mathrm{HC}$ is a potent agent in the inhibition of STAT3 with more favorable pharmacological activity than curcumin, and HC may have translational potential as an effective cancer therapeutic or preventive agent for human breast carcinoma.
\end{abstract}

\section{Introduction}

Many anticancer therapies currently in use are inadequate not only in terms of their therapeutic efficacy but also because they have undesirable side effects. On the other hand, certain dietary constituents known as phytochemicals have been shown to have significant anticancer efficacy (1) while causing minimal deleterious side effects.

Curcumin, the active component of turmeric and a polyphenolic compound, is one of the most widely characterized phytochemicals. It has been a part of therapeutic preparations for centuries due to its wide spectrum of beneficial activities and its safety in relatively large dose (2). Evidence has been shown that curcumin inhibits the initiation, progression

Correspondence to: Dr Tingmei Chen, Key Laboratory of Diagnostic Medicine Designated by the Ministry of Education, Chongqing Medical University, Chongqing 400016, P.R. China

E-mail: chentingmei@sohu.com

*Contributed equally

Key words: curcumin analogue, signal transducer and activator of transcription 3, breast cancer and continued survival of cancers cells (3). On basis of its numerous anti-carcinogenic properties, curcumin has already been the subject of several clinical trials for use as a treatment in human cancers. However, the low bioavailability prevents its use in chemotherapeutic application, and one potential means of circumventing this problem has been the creation of synthetic curcumin analogues. Hydrazinocurcumin (HC) (Fig. 1), a synthetic analogue of curcumin, was obtained as pale yellow gum which was analyzed for $\mathrm{C}_{21} \mathrm{H}_{20} \mathrm{~N}_{2} \mathrm{O}_{4}$ by HRMS, thus $13^{\circ}$ of unsaturation (4). Compared with curcumin, $\mathrm{HC}$ has greatly improved water solubility and stability, and has high cell permeability, or improved bioavailability with more favorable pharmacological activity (5). In our study, we compared the effects of $\mathrm{HC}$ and curcumin on carcinogenicity of breast cancers, and demonstrated for the first time that $\mathrm{HC}$ was more effective than curcumin in suppressing cell proliferation, colony formation, cell migration, invasion, and induction apoptosis in human breast cancer cells (MDA-MB-231, MCF-7), along with inhibition of STAT3 phosphorylation (Tyr705) and downregulation of STAT3 downstream targets. Therefore, we concluded that $\mathrm{HC}$ is substantially more effective than curcumin in vitro.

\section{Materials and methods}

Cell lines and reagents. The human breast cancer cell lines MDA-MB-231 and MCF-7 were obtained from Institute of Cell Research, Chinese Academy of Sciences. These cell lines were grown at $37^{\circ} \mathrm{C}$ in Dulbecco's modified Eagle's medium (DMEM) with $10 \%$ fetal bovine serum (FBS, Sijiqing, China) in a humidified $5 \% \mathrm{CO}_{2}$ incubator. All cells were washed three times in $\mathrm{pH}$ 7.4 PBS before harvesting for different experiments. Curcumin and HC were synthesized and provided kindly by Dr Yanmei Zhang at Carlifornia University of San Diego, the purity was $>98 \%$.

MTT cell viability assay. Breast cancer cell lines (MDAMB-231, MCF-7) were seeded in 96-well plates at a density of 3,000 cells per well. Different concentrations of curcumin (2.5-40 $\mu \mathrm{M})$ or hydrazinocurcumin $(0.5-5 \mu \mathrm{M})$ were added in triplicate to the plates in the presence of $10 \%$ FBS. The cells were incubated at $37^{\circ} \mathrm{C}$ for $72 \mathrm{~h}$. Then $25 \mu \mathrm{l}$ MTT (Sigma) was added to each sample. After 3.5 h, $100 \mu$ l DMSO (Sigma) was 
added to each well. The absorbance was read at $490 \mathrm{~nm}$. The viability of the untreated cells was arbitrarily set at $100 \%$ and compared with the viability of curcumim, hydrazinocurcumintreated cells. $\mathrm{IC}_{50}$ was determined using SPSS 16.0 software.

Colony formation assay. A base $0.6 \%$ agar gel with $10 \%$ FBS in DMEM was prepared and added to the well of a 6-well culture dish. Breast cancer cells were plated at a density of 3,000 cells per well on top of the base agar for anchorage-independent growth analysis in $0.4 \%$ agar gel with $10 \%$ FBS in DMEM supplemented with curcumin, hydrazinocurcumin or DMSO. The cells were maintained at $37^{\circ} \mathrm{C}$ and allowed to grow for 2 weeks. The colonies were stained using MTT dye (100 $\mu \mathrm{l}$ per well). Pictures of the colonies were taken using a Leica MZ 16FA inverted microscope (Leica Microsystems, Bannockburn, IL) with a 7.4 Slider Camera (Diagnostic Instruments, Inc., Sterling Heights, MI). The colonies were scored by counting with an inverted microscope, and numbers were normalized as a percentage of colonies formed in DMSO treatment.

Cell cycle analysis. Cell cycle phase was determined by fluores-cence-activated cell sorting analysis. MDA-MB231 and MCF-7 cells were inoculated into 6-well plates at a concentration of $5 \times 10^{5}$ per well, exposed to curcumin and $\mathrm{HC}$ at a concentration of $10 \mu \mathrm{M}$, cultured for 24 and $48 \mathrm{~h}$, collected, and sorted using flow cytometry (Bekman Coulter, USA) as described previously (6).

Apoptosis rate analysis. MDA-MB-231 and MCF-7 cells were grown for $24 \mathrm{~h}$ in a $6-\mathrm{mm}$ plate and then treated with the $10 \mu \mathrm{M}$ of curcumin and $\mathrm{HC}$ for 24 and $48 \mathrm{~h}$. Cells were washed by PBS 3 times, and then digested with $0.25 \%$ tryptan-EDTA. After centrifugation, cells were resuspended in $0.5 \mathrm{ml}$ PBS. Cells were then stained with Annexin V and propidium iodide (PI) in the presence of $100 \mathrm{mg} / \mathrm{ml}$ RNAse and $0.1 \%$ Triton X-100 for 30 min at $37^{\circ} \mathrm{C}$. Flow cytometric (Bekman Coulter) analysis was performed using a fluorescence-activated cell sorter.

Wound healing/cell migration assay. Breast cancer cells ( $3 \times 10^{5}$ per well) were seeded in a 6-well plate. Approximately $24 \mathrm{~h}$ later, when the cells were $100 \%$ confluent, the monolayer was scratched using a 1-ml pipette tip and washed once to remove nonadherent cells. New medium in the presence of $10 \%$ FBS containing curcumin, hydrazinocurcumin or DMSO was added. The treatments were removed after $4 \mathrm{~h}$, the fresh medium was added. After an additional $20 \mathrm{~h}$ without treatment, the cells were observed under a microscope. When the wound in the control was closed, the inhibition of migration was assessed by using the ImageJ software, available from the National Institutes of Health Web site (http://rsb.info.nih. gov/ij). The percent of wound healed was calculated using the formula: 100-[(final area/initial area) x 100\%].

Invasion (transwell) assay. To evaluate the effects of curcumin and $\mathrm{HC}$ on the invasion ability of MDA-MB-231 and MCF-7 cells, the cells were harvested by trypsinization after treatment for $24 \mathrm{~h}$ with curcumin and $\mathrm{HC}$ at doses of 10,20 $\mu \mathrm{mol} / \mathrm{l}$. Cells were then seeded at a density of 50,000 cells in $0.2 \mathrm{ml}$ in upper compartment. In the lower compartment $0.5 \mathrm{ml}$ of medium was supplemented with $15 \%$ FBS. After incubation for $24 \mathrm{~h}$, the
Table I. $\mathrm{IC}_{50}(\mu \mathrm{M})$ of $\mathrm{HC}$ and curcumin in breast cancer cells.

\begin{tabular}{lcc}
\hline Cell line & Curcumin & HC \\
\hline MDA-MB-231 & 26.9 & 3.37 \\
MCF-7 & 21.22 & 2.56 \\
\hline
\end{tabular}

Cancer cells were treated for $72 \mathrm{~h}$, and cell viability was analyzed by MTT assays. $\mathrm{IC}_{50}$ value $(\mu \mathrm{M})$ was subsequently determined for each cell line.

upper cell layer was removed with a cotton swab, and the cells on the lower side were fixed with $4 \%$ formaldehyde solution. Subsequently, cells were stained with crystal viola and counted under a microscope.

Western blot analysis. Breast cancer cell lines (MDA-MB-231, MCF-7) were treated with curcumin (10 or $20 \mu \mathrm{M}$, hydrazinocurcumin $(10$ or $20 \mu \mathrm{M})$ or DMSO for $24 \mathrm{~h}$. For Western blot analysis, the protein from cancer cell lysates were subjected to SDS-PAGE and transferred to PVDF membrane. Blots were probed with phosphospecific STAT3 (Tyr 705) antibody (Cell Signaling Technologies), with STAT3 antibody (BD), with c-Myc, Mcl-1, Bcl-xl, survivin, MMP-9, MMP-2 antibodies (Bioword), with cyclin D1, VEGF, Bcl-2, BAX, $\beta$-actin antibodies (Santa Cruz Biotechnology), with PARP, caspase 9 antibodies (Beyotime). Membranes were analyzed using enhanced chemiluminescence (ECL) detection system (Viagene).

\section{Results}

HC and curcumin inhibit cell viability in human breast cancer cells. A dose-dependent inhibition in tumor cell proliferation/ viability was observed after $72 \mathrm{~h}$ of treatment, and $\mathrm{IC}_{50}$ values were calculated for curcumin and HC (Table I). The results showed that compared with curcumin, HC was substantially more potent in inhibiting cell viability in both cell lines.

Anchorage-independent growth and cell viability. The ability of transformed cells to grow and proliferate in the absence of substratum attachment is one of the hallmarks of malignancy and vitally important in the formation of the tumor (7). It was showed that treatment with curcumin and HC led to decreased colony formation in soft agar in both two cell lines (Fig. 2). Compared with the DMSO control samples, a $5 \mu \mathrm{mol} / 1$ concentration of curcumin elicited a decrease of $\sim 50 \%$ in colony formation, while equal concentration of $\mathrm{HC}$ showed $\sim 95 \%$ reduction in colony number.

$H C$ and curcumin arrest the cell cycle in human breast cancer cells. As shown (Fig. 3), HC and curcumin treatment at a concentration of $10 \mu \mathrm{M}$ significantly increased the cell number in the $\mathrm{G}_{1}$ phase in MDA-MB-231 and MCF-7 ( $<<0.05$ compared with control), and $\mathrm{HC}$ was more potent than curcumin in arresting the cells cycle in $\mathrm{G}_{1}$ phase.

HC and curcumin induce cell apoptosis in human breast cancer cells. At a sufficiently high dose, curcumin induces apoptosis of 


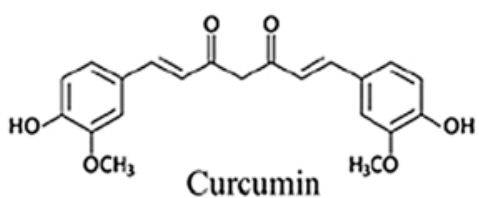<smiles>CCc1cc(/C=C/c2ccc(/C=C/c3ccc(O)c(CC)c3)cc2)ccc1C</smiles>

Figure 1. Chemical structures of curcumin and $\mathrm{HC}$

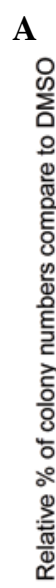

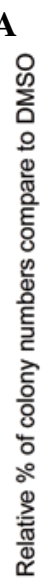

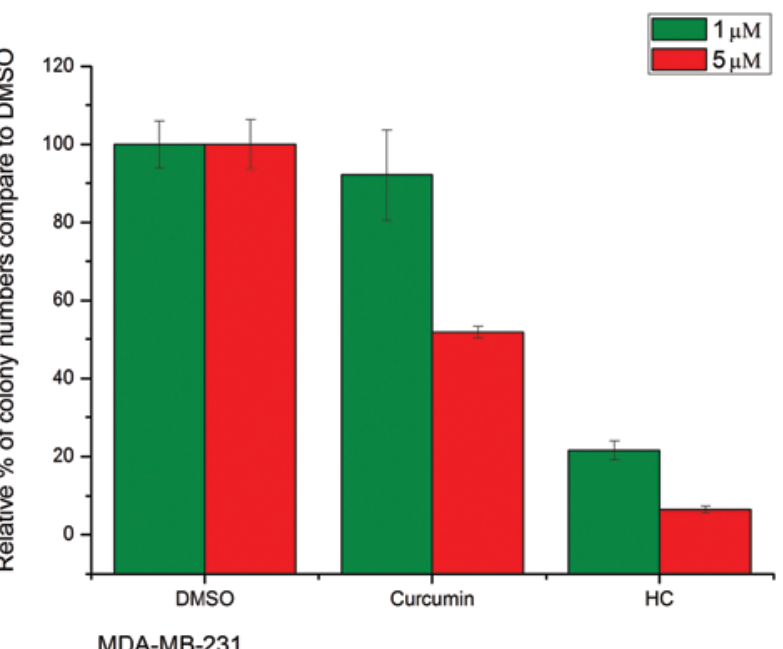

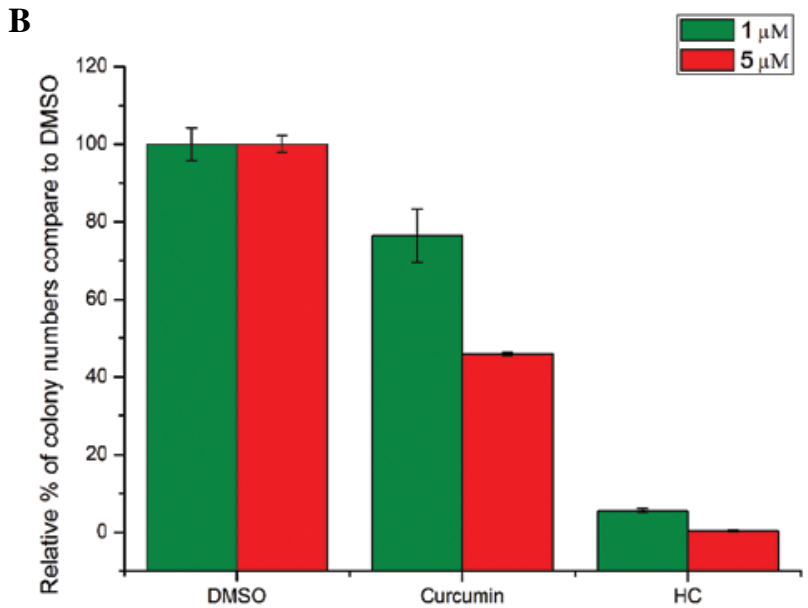

MCF-7

Figure 2. Colony formation assay. Colony formation of breast cancer cells in soft agar was inhibited by curcumin and HC. The potency of curcumin and HC were assessed in an anchorage-independent environment through a colony formation assay. Treatment with $1,5 \mu \mathrm{mol} / 1$ curcumin and $\mathrm{HC}$ for 2 weeks greatly decreased the ability of MDA-MB-231 (A), MCF-7 (B) cells to form colonies in comparison to DMSO control ( $<<0.05$ ).

A

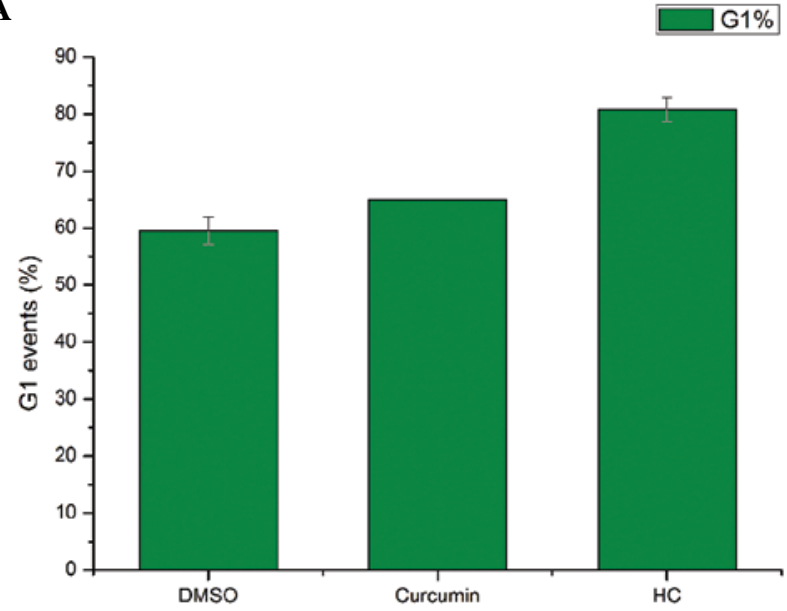

MDA-MB-231
B

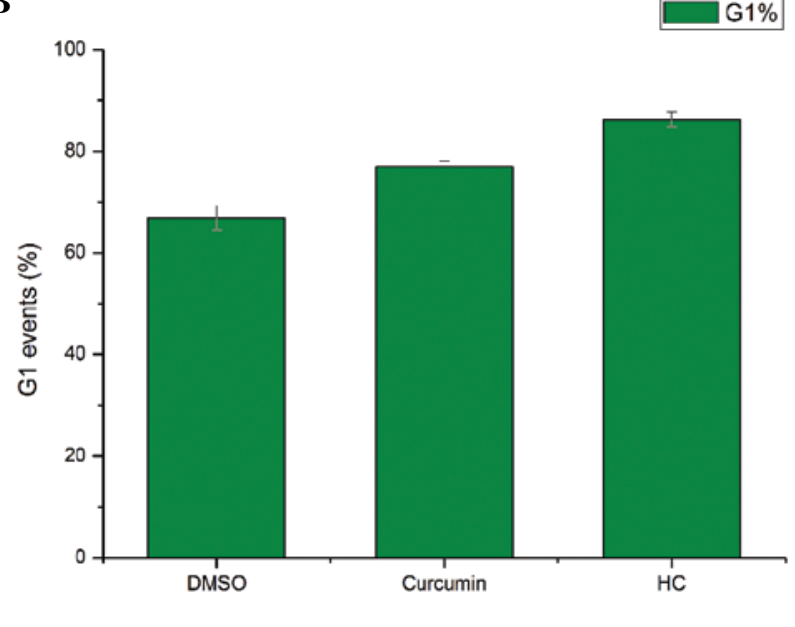

MCF-7

Figure 3. Cell cycle analysis. Treatment with $10 \mu \mathrm{M}$, curcumin and $\mathrm{HC}$ for $48 \mathrm{~h}$ had an effect on cell cycle progression of MDA-MB-231 and MCF-7 breast cancer cells as determined by FCM. Increased percentage of cells in $\mathrm{G}_{1}$ phase was observed in MDA-MB-231 (A), MCF-7 (B).

many cancer cells including breast cancer cells. We assessed the effect of $\mathrm{HC}$ and curcumin on the induction of apoptosis in MDA-MB-231 and MCF-7 cells by FCM. The results (Fig. 4) showed that $\mathrm{HC}$ dose-dependently increased cells apoptotic rate after 48 -h treatment; $\mathrm{HC}$ at $10 \mu \mathrm{mol} / \mathrm{l}$ significantly induced cells apoptosis (14\% in MDA-MB-231 cells and $26 \%$ in MCF-7 cells), and at the same concentration, curcumin only induced 9 and 20\% cells apoptosis in MDA-MB-231 and MCF-7 cells, respectively. In addition, PARP and caspase 9 are key effector molecules in the apoptosis pathway, and the enhancement of the level of the two molecules were also observed within $24 \mathrm{~h}$ in both MDA-MB-231 and MCF-7 cells treated with 10-20 $\mu \mathrm{M}$ curcumin and $\mathrm{HC}$.

HC and curcumin inhibit cell migration in human breast cancer cells. Cell migration is necessary in many physiological processes, such as wound healing and tumor metastasis. To investigate the effect of $\mathrm{HC}$ on cell migration, a wound healing 
A

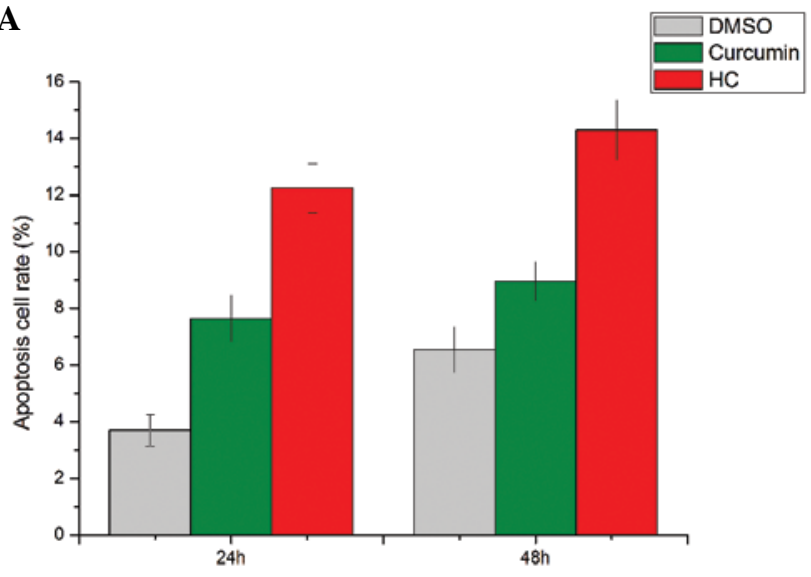

MDA-MB-231

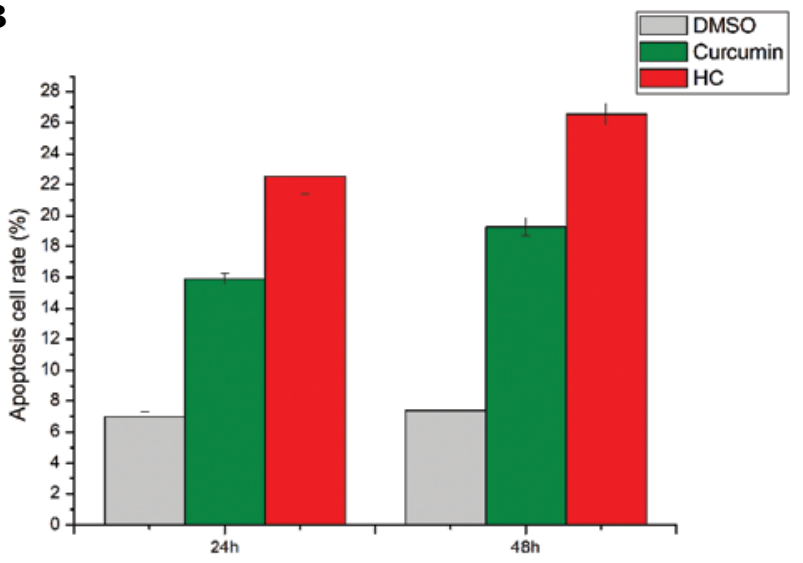

MCF-7

Figure 4. Apoptosis rate analysis. Induction of breast cancer cell apoptosis by curcumin and HC. Treatment with $10 \mathrm{M}$ curcumin and $\mathrm{HC}$ for 24 and $48 \mathrm{~h}$ induced apoptosis in MDA-MB-231 (A), MCF-7 (B) cells as determined by FCM.

A

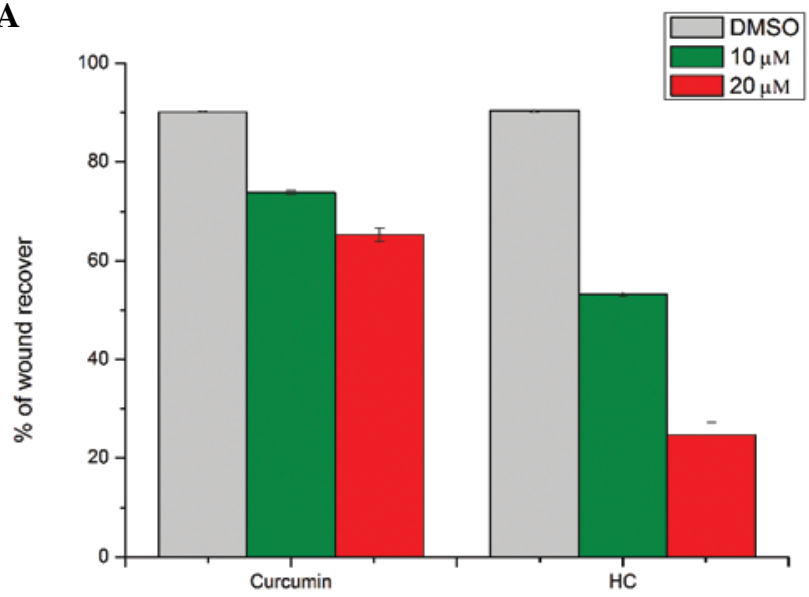

MDA-MB-231

C

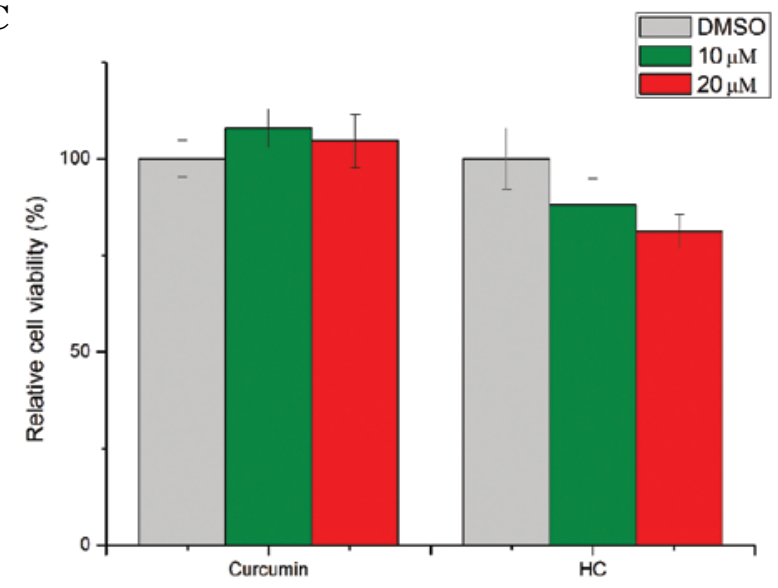

MDA-MB-231
B

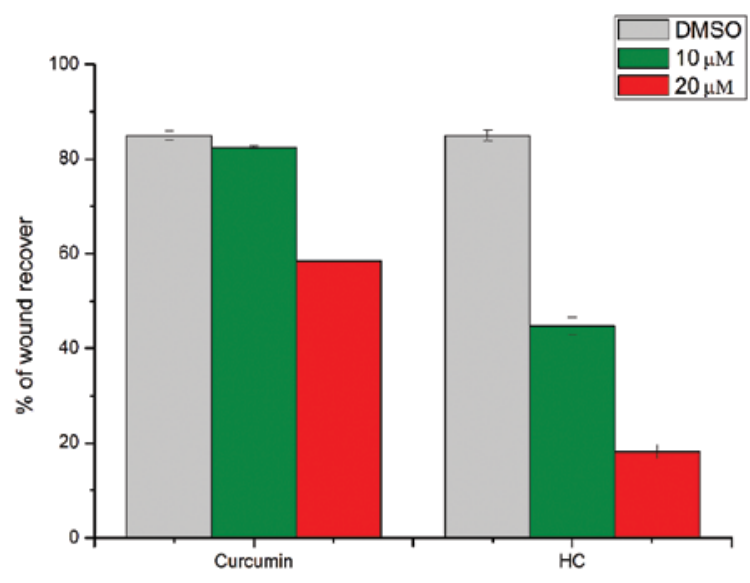

MCF-7

D

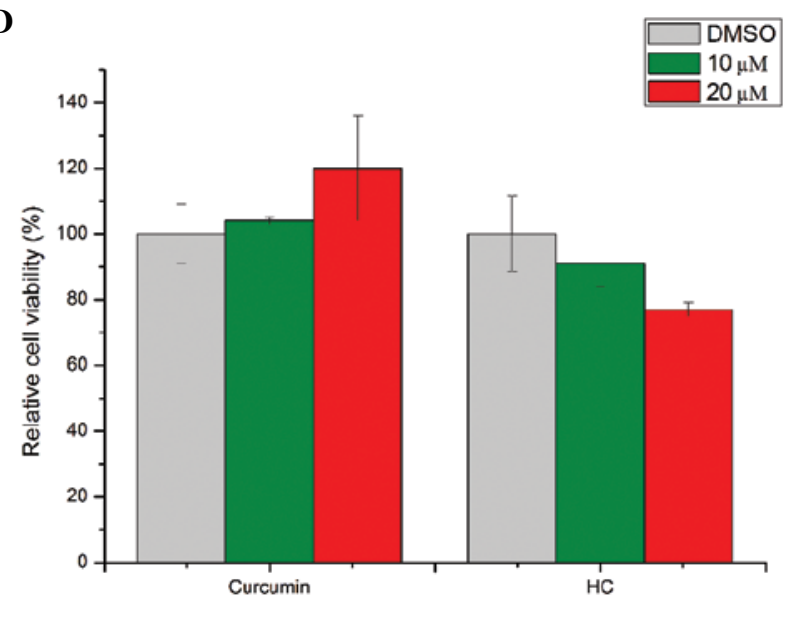

MCF-7

Figure 5. Wound healing assay. Curcumin and $\mathrm{HC}$ had an impact on breast cancer cells migration. Migration of breast cancer cells into a scratch wound was impeded after $4 \mathrm{~h}$ of treatment with 10 and $20 \mu \mathrm{M}$ curcumin and HC. (A) MDA-MB-231, (B) MCF-7. MTT assays of MDA-MB-231 (C) and MCF-7 (D) cells revealed that the dosages of these agents used in the migration assay had minimal impact on viability over $4 \mathrm{~h}$ of drug treatment and an additional $20 \mathrm{~h}$ without treatment.

assay was carried out with MDA-MB-231 and MCF-7 breast cancer cells. After the creation of a wound, cells were treated with various concentrations of $\mathrm{HC}$ and curcumin. Treatment was removed after $4 \mathrm{~h}$ and cells were returned to standard media in an attempt to minimize any cytotoxic effects that could potentially confound our observations. Following $20 \mathrm{~h}$ of further incubation, 
A

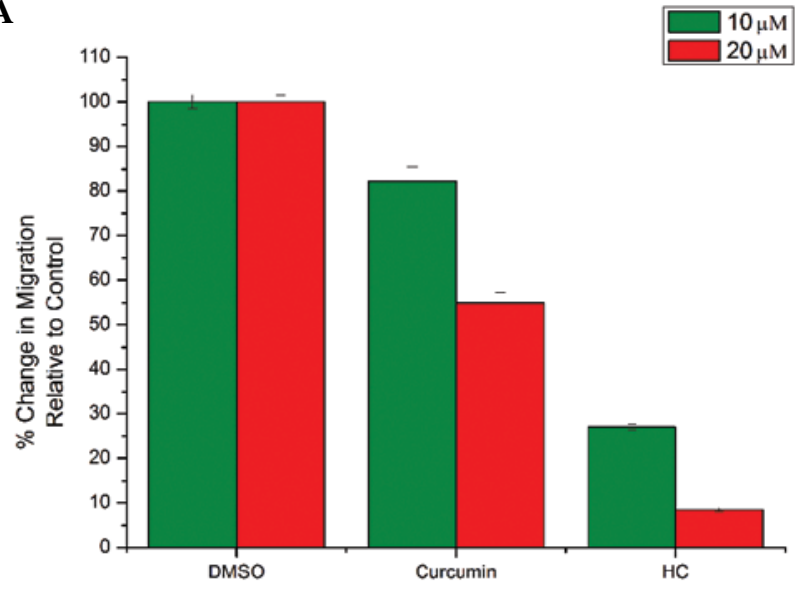

MDA-MB-231
B

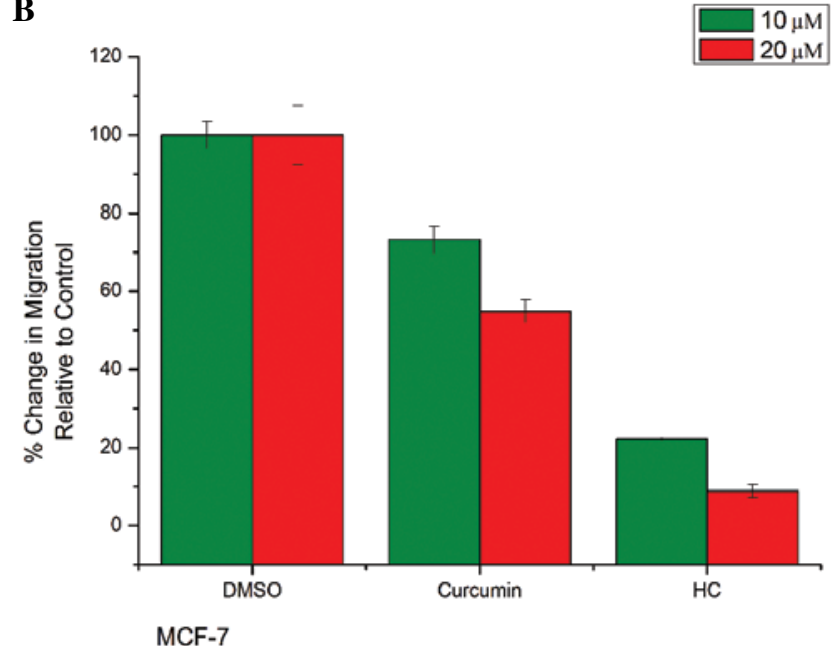

Figure 6. Invasion assay. Curcumin and HC inhibit invasion of breast cancer cells. Treatment of MDA-MB-231 (A) and MCF-7 (B) by 10 and $20 \mu \mathrm{M}$ curcumin and $\mathrm{HC}$ for $24 \mathrm{~h}$ significantly reduced cell invasive behavior as assessed by transwell assay. Microscopic images reflect representative crystal violet staining of migrated MDA-MB231 cells $24 \mathrm{~h}$ after treatment.

the areas of the wounds were measured using ImageJ software. Treatment with $\mathrm{HC}$ at a concentration of $10 \mu \mathrm{M}$ or higher caused a significant decrease in cell migration $(\mathrm{p}<0.05)$ (Fig. 5). Because MTT assay revealed that the dosages and time points used in migration assay had minimal impact on cell viability (Fig. 5), the ability of HC and curcumin to inhibit cell migration might not be due to its ability to inhibit cell proliferation.

$H C$ and curcumin suppress cell invasion in human breast cancer cells. To determine the role of curcumin and $\mathrm{HC}$ in cell invasion, MDA-MB-231 and MCF-7 cells were treated with indicated concentrations of curcumin and $\mathrm{HC}$ for $24 \mathrm{~h}$. Both $\mathrm{HC}$ and curcumin significantly inhibited the invasion of two cell lines (Fig. 6). Interestingly, compared with the DMSO control, the invasion of MDA-MB-231 and MCF-7 cells was inhibited by $\sim 90 \%$ at the concentration of $20 \mu \mathrm{M}$ of $\mathrm{HC}$, and equal administration of curcumin showed $\sim 50 \%$ reduction in cell number.

$H C$ and curcumin inhibit the expression of STAT3 protein and its downstream targets in human breast cancer cells. As previously mentioned, STAT3 binding to the promoters of the target genes induces the transcription of several proteins involved in carcinogenicity of cancer cells. As seen in Western blot assay (Fig. 7), HC was more potent than curcumin in inhibiting the expression of STAT3 protein at the same concentration (10-20 $\mu \mathrm{M})$ in MDA-MB-231 and MCF-7 cells. To further analyze the expression of the downstream targets of STAT3, Western blotting was run for MMP-9, MMP-2, Mcl-1, cyclin D1, c-myc, Bcl-xl, Bcl-2, survivin and VEGF, and it found that treatment with $\mathrm{HC}$ resulted in more inhibition of the expression of these targets of STAT3 than curcumin.

\section{Discussion}

The dysregulation of multiple oncogenic pathways is common among many cancers, including breast cancer cells. Being a phytochemical, anticancer efficacy of curcumin is mediated through regulating various transcription factors, growth factors, inflammatory cytokines, protein kinases, and other enzymes
(8). Persistent activation of signal transduction and activators of transcription-3 (STAT3) is found with high frequency in a wide range of human cancer cell lines and tissues and implicated in stimulating cell proliferation, promoting angiogenesis, invasion and migration, mediating immune evasion, and conferring increased resistance to apoptosis (9-14). As one of the most important curcumin molecular targets, STAT3 can also be down-regulated effectively by curcumin $(15,16)$.

STAT3 activation occurs when the tyrosine 705 (Tyr705) residue is phosphorylated, and then leads to dimerization and translocation from the cytoplasm to the nucleus (17-19). In the nucleus, STAT3 binding to target genes induces the transcription $(20,21)$. Stat 3 drives malignant progression through the deregulation of key proteins, including cell survival proteins such as Bcl-XL, Bcl-2, Mcl-1 and survivin (10,22-26), cell growth proteins such as cyclin D1/D2 and c-myc (9,27-31), inducers of angiogenesis such as vascular endothelial growth factor (VEGF) $(32,33)$, and stimulators of invasion and metastasis such as MMP-2, MMP-9 (34-37). The crucial role of STAT3 in cancer progression and tumorigenesis suggests that it is a promising molecular target for cancer treatment.

Although curcumin has been shown to be a safe and effective inhibitor of STAT3, its low bioavailability prevents its chemotherapeutic application. In this study, we characterized the biologic activity of HC, a curcumin analog with improved water solubility, higher cell permeability and more favorable pharmacological activity; we evaluated for the first time the inhibitory efficacy of $\mathrm{HC}$ and curcumin in two breast cancer cells, MDA-MB-231 and MCF-7, which present constitutive activation of STAT3.

By both annexin V/PI staining and detection of cleavage of caspase 9, and PARP, it showed that compared with curcumin, $\mathrm{HC}$ increased the efficacy of induction of apoptosis of breast cancer cells. Accordingly, Bcl-2, Bcl-xl and Mcl-1, which are well-known apoptosis inhibitors and downstream target genes of STAT3, decreased after treatment with $\mathrm{HC}$ and curcumin. $\mathrm{Bcl}-\mathrm{xl}$ and $\mathrm{Bcl}-2$ are the anti-apoptotic protein within the Bcl-2 family that inhibits apoptosis by binding proapoptotic proteins and preventing cytochrome c release (38-40). Mcl-1 

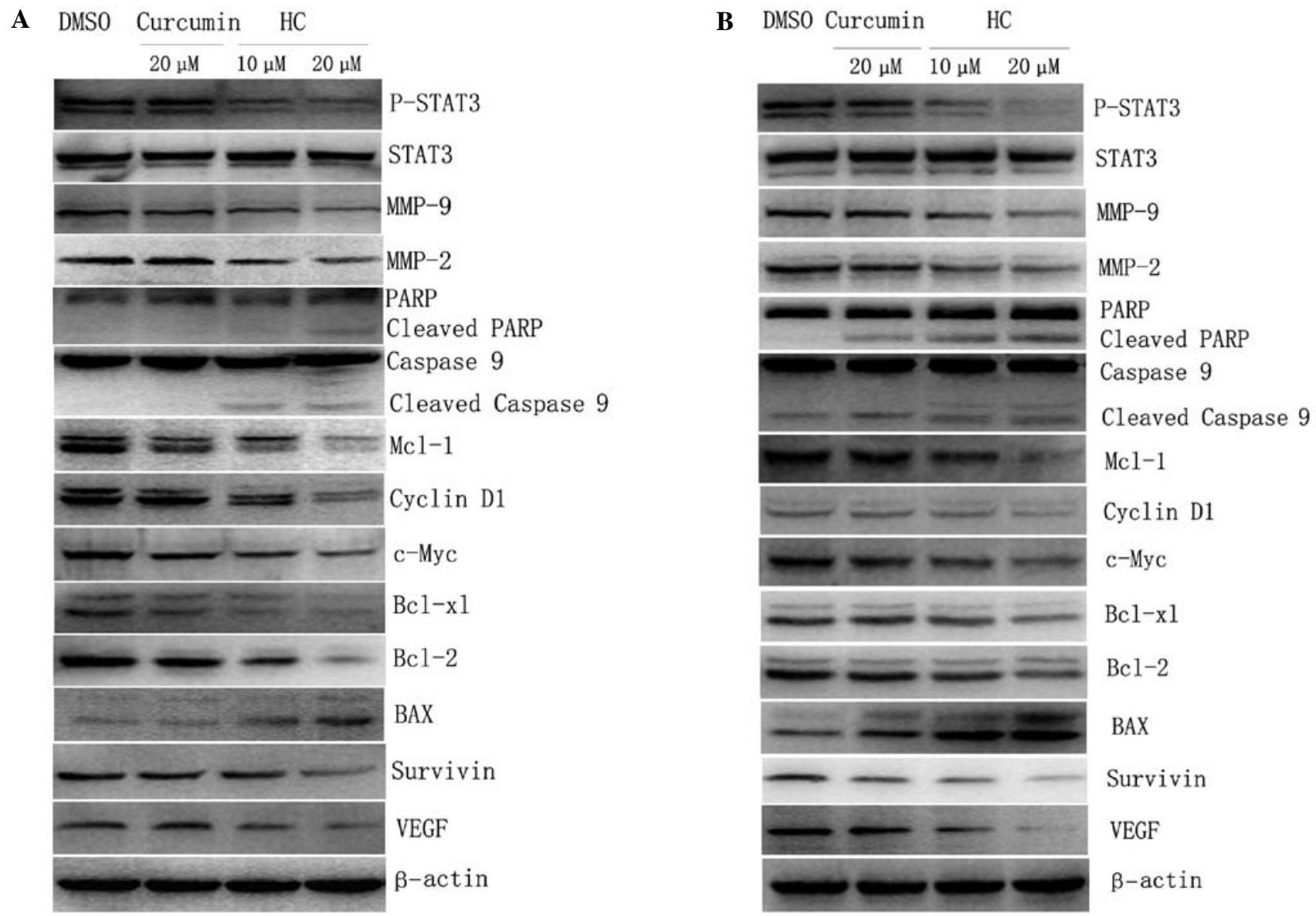

Figure 7. Expression of STAT3 and its downstream targets by Western blot analysis. Western blot analysis of cells treated with curcumin and HC. Both cancer cell lines express constitutively active STAT3. (A) MDA-MB-231, (B) MCF-7, exhibited decreased expression of STAT3 phosphorylation after treatment with 10 and $20 \mu \mathrm{M} / 1$ curcumin and HC for $24 \mathrm{~h}$. Downstream targets of STAT3, including MMP-9, MMP-2, Mcl-1, cyclin D1, c-Myc, Bcl-xl, Bcl-2, survivin, and VEGF were also inhibited. Cell apoptosis is indicated by the induction of cleaved PARP, cleaved caspase 9 and BAX.

also represents a survival factor for human cancer cells $(23,41)$ In addition, survivin is one of the key regulators of both cell cycle and apoptosis (42), and was shown in our study to be down-expressed.

The results of FCM also showed that treatment with curcumin and $\mathrm{HC}$ resulted in $\mathrm{G}_{1}$ arrest of cancer cells, and the decreased expression of cyclin D1 and c-Myc by Western blotting might account for proliferation inhibition and cell cycle arrest of the treated cells. Previous studies confirmed that Stat3 made an essential contribution to the regulation of cyclin D1 and c-Myc in v-Src transformation (43). Overexpression of cyclin D1 drives oncogenesis to regulate cell cycle progression (44). The c-Myc protooncogene is over-expressed in Burkett's lymphoma, and in other carcinomas such as breast cancer and colon cancer where it contributes to increased cellular proliferation and inhibition of differentiation (45-47).

The wound healing assay and transwell assay demonstrated that $\mathrm{HC}$ was more potent than curcumin in reducing the ability of migration and invasion of MDA-MB-231 and MCF-7 cells, and the level of MMP-2 and MMP-9 were also decreased. Constructive expression of STAT3 can up-regulate the expression of MMP-2 and MMP-9, which are able to efficiently degrade the extracellular matrix and basement membrane, promoting invasion and metastasis of cancer cells (34). Recent studies have found that the activity of STAT3 is closely related to the expression of MMP-9 in human breast cancer, and the activity of MMP-9, in epithelial cells of breast cancer, was significantly increased due to the sustained activation of the transformation of the plasmid by STAT3 (35). Thus, STAT3 may promote the progression of breast cancer through the regulation on MMP-9. Other studies have confirmed that MMP-2 might be the downstream target gene of STAT3; when it is translocated to the nucleus, phosphorylated STAT3 can bind to the promoter of MMP-2 to regulate MMP-2 expression $(36,37)$.

In conclusion, our results showed that compared with curcumin, HC was more effective in inhibiting STAT3 phosphorylation and down-regulating an array of STAT3 downstream targets which contributed to the suppression of cell proliferation, loss of colony formation, depressing cell migration and invasion as well as induction of cell apoptosis. It was concluded that HC is a potent agent in inhibiting the phosphorylation of STAT3 with a more favorable pharmacological activity than curcumin, and $\mathrm{HC}$ might have translational potential as an effective drug or preventive agent for human breast carcinoma.

\section{Acknowledgements}

We thank Dr Yanmei Zhang at California University of San Diego for providing $\mathrm{HC}$, and Ju Cao at Chongqing Medical University for language support. This work was supported by a 
grant from National Natural Science Foundation of China (No. 30971131); grants from Chongqing Science \& Technology Commission (the Natural Science Foundation of Chongqing, CSTC 2009BB5077); grants from Foundation of National Key Discipline in Laboratory Medicine (No. 2010104). This work was supported in part by Key Laboratory of Diagnostic Medicine Designated by the Ministry of Education, Chongqing Medical University.

\section{References}

1. Surh YJ: Cancer chemoprevention with dietary phytochemicals Nat Rev Cancer 3: 768-780, 2003.

2. Goel A, Kunnumakkara AB and Aggarwal BB: Curcumin as 'Curecumin': from kitchen to clinic. Biochem Pharmacol 75: 787-809, 2008

3. Hatcher H, Planalp R, Cho J, Torti FM and Torti SV: Curcumin from ancient medicine to current clinical trials. Cell Mol Life Sci 65: 1631-1652, 2008

4. Shim JS, Kim DH, Jung HJ, et al: Hydrazinocurcumin, a novel synthetic curcumin derivative, is a potent inhibitor of endothelial cell proliferation. Bioorg Med Chem 10: 2987-2992, 2002.

5. Rathore R, Jain JP, Srivastava A, et al: Simultaneous determination of hydrazinocurcumin and phenol red in samples from rat intestinal permeability studies: HPLC method development and validation. J Pharm Biomed Anal 46: 374-380, 2008.

6. Kakudo Y, Shibata H, Otsuka K, Kato S and Ishioka C: Lack of correlation between p53-dependent transcriptional activity and the ability to induce apoptosis among 179 mutant p53s. Cancer Res 65: 2108-2114, 2005.

7. Hanahan D and Weinberg RA: The hallmarks of cancer. Cell 100: 57-70, 2000.

8. Heng MC: Curcumin targeted signaling pathways: basis for antiphotoaging and anti-carcinogenic therapy. Int J Dermatol 49 608-622, 2010.

9. Yu H and Jove R: The STATs of cancer - new molecular targets come of age. Nat Rev Cancer 4: 97-105, 2004.

10. Alas S and Bonavida B: Inhibition of constitutive STAT3 activity sensitizes resistant non-Hodgkin's lymphoma and multiple myeloma to chemotherapeutic drug-mediated apoptosis. Clin Cancer Res 9: 316-326, 2003

11. Buettner R, Mora L and Jove R: Activated STAT signaling in human tumors provides novel molecular targets for therapeutic intervention. Clin Cancer Res 8: 945-954, 2002.

12. Shen Y, Devgan G, Darnell JJ and Bromberg J: Constitutively activated Stat 3 protects fibroblasts from serum withdrawal and UV-induced apoptosis and antagonizes the proapoptotic effects of activated Stat1. Proc Natl Acad Sci USA 98: 1543-1548, 2001

13. Real P, Sierra A, De Juan A, Segovia J, Lopez-Vega J and Fernandez-Luna J: Resistance to chemotherapy via Stat3dependent overexpression of $\mathrm{Bcl}-2$ in metastatic breast cancer cells. Oncogene 21: 7611-7618, 2002.

14. Wang T, Niu G, Kortylewski M, et al: Regulation of the innate and adaptive immune responses by Stat-3 signaling in tumor cells. Nat Med 10: 48-54, 2004.

15. Aggarwal BB and Shishodia S: Molecular targets of dietary agents for prevention and therapy of cancer. Biochem Pharmaco 71: 1397-1421, 2006

16. Bharti A, Donato N and Aggarwal B: Curcumin (diferuloylmethane) inhibits constitutive and IL-6-inducible STAT3 phosphorylation in human multiple myeloma cells. J Immunol 171: 3863-3871, 2003.

17. Bowman T, Garcia R, Turkson J and Jove R: STATs in oncogenesis. Oncogene 19: 2474-2488, 2000.

18. Kaptein A, Paillard V and Saunders M: Dominant negative stat3 mutant inhibits interleukin-6-induced Jak-STAT signal transduction. J Biol Chem 271: 5961-5964, 1996.

19. Faruqi T, Gomez D, Bustelo X, Bar-Sagi D and Reich N: Rac1 mediates STAT3 activation by autocrine IL-6. Proc Natl Acad Sci USA 98: 9014-9019, 2001.

20. Bromberg J and Darnell JE Jr: The role of STATs in transcriptional control and their impact on cellular function. Oncogene 19: 2468-2473, 2000.

21. Bromberg JF, Wrzeszczynska MH, Devgan G, Zhao Y, Pestell RG Albanese C and Darnell JE Jr: Stat3 as an oncogene. Cell 98: 295-303, 1999
22. Catlett-Falcone R, Landowski TH, Oshiro MM, et al: Constitutive activation of Stat 3 signaling confers resistance to apoptosis in human U266 myeloma cells. Immunity 10: 105-115, 1999.

23. Epling-Burnette PK, Lui JH, Catlette-Falcone R, et al: Inhibition of STAT3 signaling leads to apoptosis of leukemic large granular lymphocytes and decreased Mcl-1 expression. J Clin Invest 107: 351-362, 2001.

24. Alas S and Bonavida B: Rituximab inactivates signal transducer and activation of transcription 3 (STAT3) activity in B-non-Hodgkin's lymphoma through inhibition of the interleukin 10 autocrine/ paracrine loop and results in down-regulation of Bcl-2 and sensitization to cytotoxic drugs. Cancer Res 61: 5137-5144, 2001.

25. Gritsko T, Williams A, Turkson J, et al: Persistent activation of stat3 signaling induces survivin gene expression and confers resistance to apoptosis in human breast cancer cells. Clin Cancer Res 12: 11-19, 2006

26. Diaz N, Minton S, Cox C, et al: Activation of stat3 in primary tumors from high-risk breast cancer patients is associated with elevated levels of activated SRC and survivin expression. Clin Cancer Res 12:20-28, 2006.

27. Bromberg JF: Activation of STAT proteins and growth control. Bioessays 23: 161-169, 2001.

28. Darnell JE Jr: Transcription factors as targets for cancer therapy. Nat Rev Cancer 2: 740-749, 2002.

29. Darnell JE: Validating Stat3 in cancer therapy. Nat Med 11: 595-596, 2005.

30. Turkson J: STAT proteins as novel targets for cancer drug discovery. Expert Opin Ther Targets 8: 409-422, 2004.

31. Kim DJ, Chan KS, Sano S and Digiovanni J: Signal transducer and activator of transcription 3 (Stat3) in epithelial carcinogenesis. Mol Carcinog 46: 725-731, 2007.

32. Xi S, Gooding WE and Grandis JR: In vivo antitumor efficacy of STAT3 blockade using a transcription factor decoy approach:implications for cancer therapy. Oncogene 24: 970-979, 2005.

33. Niu G, Wright KL, Huang M, et al: Constitutive Stat3 activity upregulates VEGF expression and tumor angiogenesis. Oncogene 21: 2000-2008, 2002.

34. Xie TX, Huang FJ, Aldape KD, et al: Activation of Stat3 in human melanoma promotes brain metastasis. Cancer Res 66: 3188-3196, 2006.

35. Lin L, Hutzen B, Ball S, et al: New curcumin analogues exhibit enhanced growth-suppressive activity and inhibit AKT and signal transducer and activator of transcription 3 phosphorylation in breast and prostate cancer cells. Cancer Sci 100 1719-1727, 2009.

36. Dechow TN, Pedranzini L, Leitch A, et al: Requirement of matrix metalloproteinase-9 for the transformation of human mammary epithelial cells by Stat3-C. Proc Natl Acad Sci USA 101: 10602-10607, 2004

37. Xie TX, Wei D, Liu M, et al: Stat3 activation regulates the expression of matrix metalloproteinase- 2 and tumor invasion and metastasis. Oncogene 23: 3550-3560, 2004.

38. Boise LH, Gonzalez-Garcia M, Postema CE, et al: Bcl-x, a bcl2-related gene that functions as a dominant regulator of apoptotic cell death. Cell 74: 597-608, 1993.

39. Gonzalez-Garcia M, Perez-Ballestero R, Ding L, et al: Bcl-xL is the major bcl-x mRNA form expressed during murine development and its product localizes to mitochondria. Development 120: 3033-3042, 1994

40. Grad JM, Zeng XR and Boise LH: Regulation of Bcl-xL: a little bit to this and a little bit to STAT. Curr Opin Oncol 12: 543-549, 2001.

41. Zhou P, Qian L, Kozopas KM and Craig RW: Mcl-1, a bcl-2 family member, delays the death of hematopoietic cells under a variety of apoptosis-inducing conditions. Blood 89: 630-643, 1997.

42. Altieri DC: Validating survivin as a cancer therapeutic target. Nat Rev Cancer 3: 46-54, 2003.

43. Calo V, Migliavacca M, Bazan V, et al: STAT proteins: from normal control of cellular events to tumorigenesis. J Cell Physiol 197: 157-168, 2003

44. Maofu FU, Wang C, Li Z, Sakamaki T and Pestell RG: Minireview: cyclin D1: normal and abnormal functions. Endocrinology 145: 5439-5447, 2004

45. Spencer CA and Groudine M: Control of c-myc regulation in normal and neoplastic cells. Adv Cancer Res 56: 1-48, 1991.

46. Marcu KB, Bossone SA and Patel AJ: Myc function and regulation. Annu Rev Biochem 61: 809-860, 1992.

47. Facchini LM and Penn LZ: The molecular role of Myc in growth and transformation: recent discoveries lead to new insights. FASEB J 12: 633-651, 1998 